National Center for Family \& Marriage Research

@ Bowling Green State University

Family Profile No. 25, 2021

\title{
Relationship Status Trends According to Age and Gender, 2019-2021
}

Author: Adrianne R. Brown \& Wendy D. Manning

Over the past few decades, there have been considerable changes in union formation in the U.S. Using data from the Current Population Survey (CPS), we examine the relationship status trends of adults aged 18-40 by age group and gender from 2019 to 2021 (amid the COVID-19 pandemic). For this profile, single is defined as those who are neither married nor cohabiting with a partner. Between 2019 and 2021, the share of adults under the age of 40 who were married declined slightly for both men and women in all age groups (except for women aged 35-39 who remained relatively constant). There were no dramatic shifts in relationship status prior to the pandemic and during the pandemic.

\section{8-24-Year-Olds}

- The share of 18-24-year-olds who were married declined modestly from 2019 to 2021 among men and women (men - 6\% to $5 \%$, women $-10 \%$ to $8 \%$ ).

- Cohabitation levels remained relatively constant for both genders, with about $7 \%$ of men and about $11 \%$ of women cohabiting.

- The percentage who were single increased slightly, from $87 \%$ to $89 \%$ of men and $80 \%$ to $82 \%$ of women.
Figure 1. Relationship Status of Adults Aged 18-24 by Gender, 2019-2021 Men 18-24 Women $18-24$

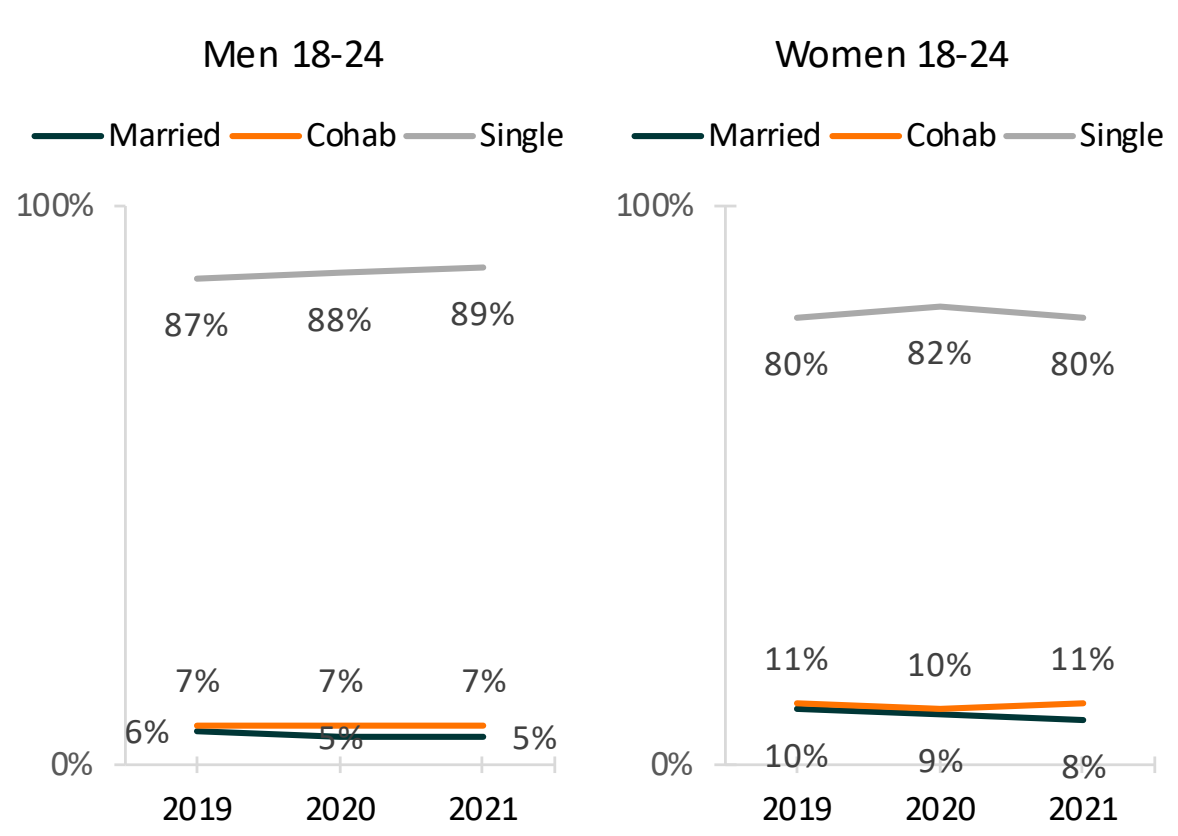

Source: NCFMR a nalyses of IPUMS-CPS, 2019-2021, University of Minnesota

Figure 2. Relationship Status of Adults Aged 25-29 by Gender, 2019-2021 Men 25-29 Women 25-29 Men 25-29 Women 25-29

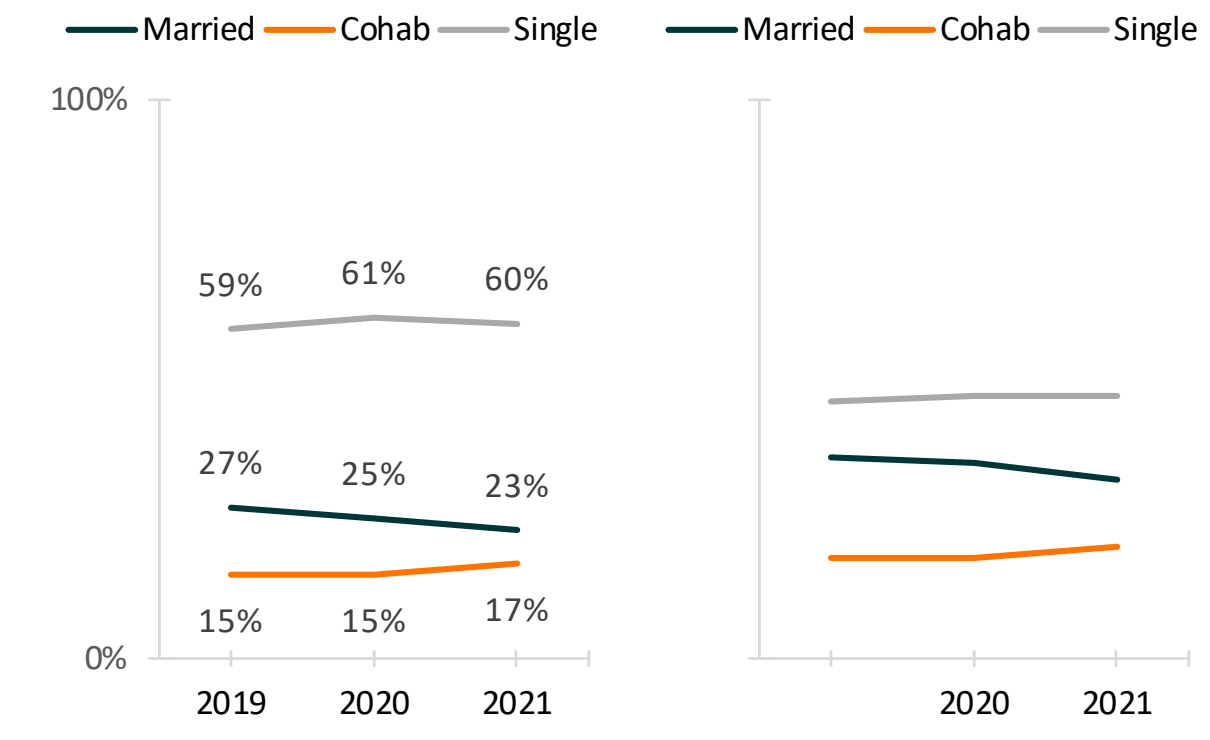

Source: NCFMR a nalyses of IPUMS-CPS, 2019-2021, University of Mi nnesota

\section{5-29-Year-Olds}

- The share of 25-29-year-old men and women who were married decreased between 2019 and 2021 from $27 \%$ to $23 \%$ among men and $36 \%$ to $32 \%$ among women.

- Cohabitation increased by two percentage points for both men and women between 2019 and 2021.

- Between 2019 and 2021 the share of singles increased slightly, reaching $60 \%$ for men and $47 \%$ for women in 2021. 
30-34-Year-Olds

- Among adults aged 30-34, the share married decreased for both men and women- $49 \%$ to $46 \%$ for men and $57 \%$ to $54 \%$ for women.

- The share cohabiting experienced a net increase over the 3-year period. Among men, the share increased from 13\% in 2019 to $15 \%$ in 2021 ; among women, the share increased from $12 \%$ to $13 \%$.

- Slight changes in singlehood occurred over the 3-year period. The share single in 2021 was 39\% among men and 33\% among women.

\section{5-39-Year-Olds}

- The share of men aged 35-39 who were married decreased by two percentage points to $59 \%$ in 2021 , and the share of women aged 35-39 who were married remained relatively constant, at $63 \%$.

- Cohabitation levels remained steady over time, with about $10 \%$ of men cohabiting and about $9 \%$ of women cohabiting.

- The percentage of men who were single increased slightly from $28 \%$ to $30 \%$ during the period, while the percentage of women who were single remained relatively constant from $28 \%$ to $27 \%$.

\section{Data Source:}

Figure 3. Relationship Status of Adults Aged 30-34 by Gender, 2019-2021
Men 30-34
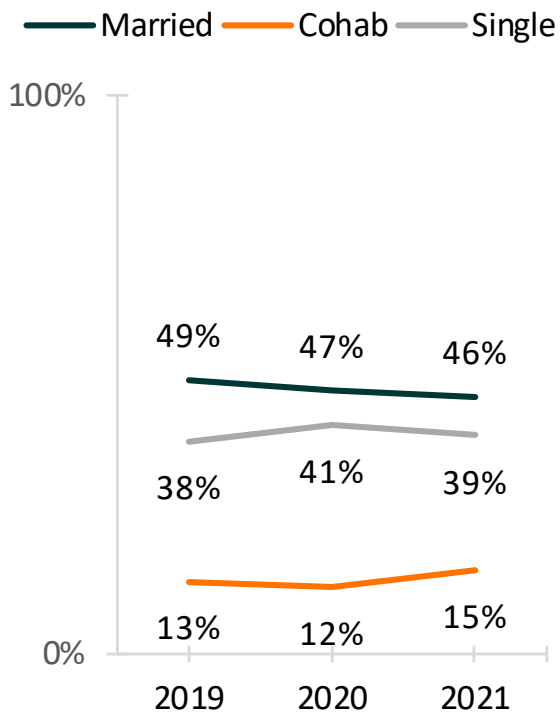

Women 30-34

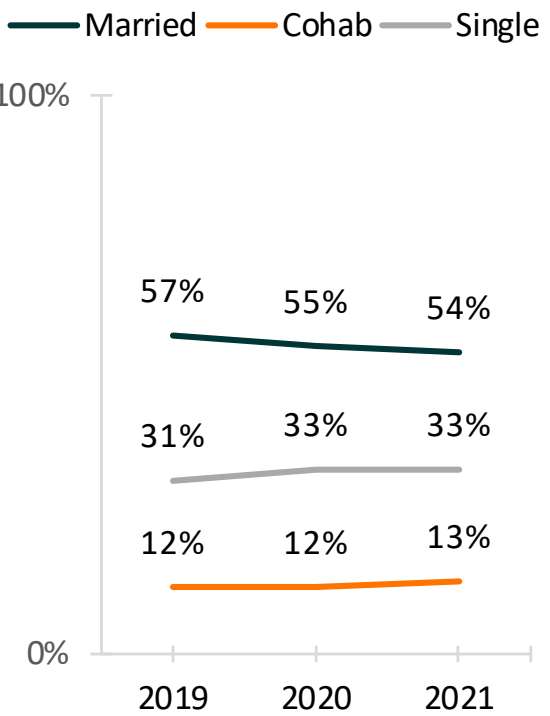

Source: NCFMR a nalyses of IPUMS-CPS, 2019-2021, University of Minnesota

Figure 4. Relationship Status of Adults Aged 35-39 by Gender, 2019-2021
Men 35-39
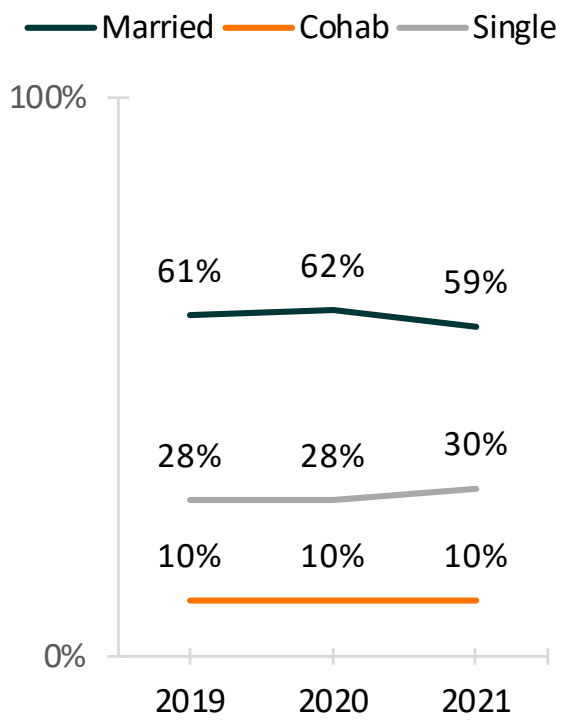

Women 35-39
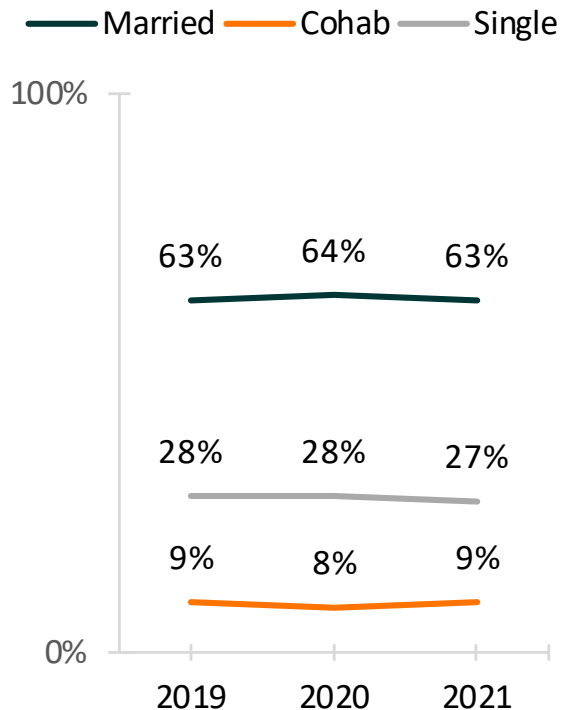

Source: NCFMR a nalyses of IPUMS-CPS, 2019-2021, University of Minnesota

Flood, S., King, M., Rodgers, R., Ruggles, S., Warren, J. R., \& Westberry, M. (2021). Integrated Public Use Microdata Series: Current Population Survey: Version 9.0 [dataset]. Minnea polis, MN: IPUMS. https://doi.org/10.18128/D030.V9.0

\section{Suggested Citation:}

Brown, A. R. \& Manning, W. D. (2021). Relationship status trends according to age and gender, 2019-2021. Family Profiles, FP-2125. Bowling Green, OH: National Center for Family \& Marriage Research. https://doi.org/10.25035/ncfmr/fp-21-25

BCSU. | National Center for

BSS. Family \& Marriage Research http://www.bgsu.edu/ncfmr

ncfmr@bgsu.edu

(419) 372-3119

This project is supported with assistance from Bowling Green State University. From 2007 to 2013, support was also provided by the U.S. Department of Health and Human Services, Office of the Assistant Secretary for Planning and Evaluation. The opinions and conclusions expressed herein are solely those of the author(s) and should not be construed as representing the opinions or policy of any agency of the state or federal government. 